\title{
DETALHES DA ARGUMENTAÇÃO NO DISCURSO RELIGIOSO MIDIÁTICO: ANÁLISE DA PREGAÇÃO “O SEGREDO DO SUCESSO NO CASAMENTO: ATENTANDO PARA OS DETALHES”
}

\section{Details of the argumentation in the media religious discourse: an analysis of the preaching "O Segredo do Sucesso no Casamento: atentando para os detalhes"}

\author{
Letícia Jovelina Storto ${ }^{1}$ \\ Vanessa Hagemeyer Burgo ${ }^{2}$ \\ Eduardo Francisco Ferreira ${ }^{3}$
}

\begin{abstract}
RESUMO
Com este artigo, objetivamos identificar as marcas linguístico-discursivas da argumentação deixadas na pregação "O segredo do sucesso no casamento: atentando para os detalhes”. Para tanto, recorremos às teorias da Semântica Argumentativa e da Linguística Textual. Para isso, realizamos uma pesquisa bibliográfica e uma pesquisa documental cujos dados receberam análise descritiva. Como resultados, observamos que, entre os recursos argumentativos utilizados pelo falante, estão a intertextualidade com a canção "Detalhes”, de Erasmo Carlos e Roberto Carlos (1971), e com o discurso bíblico, a repetição, a interrogação e o uso de marcadores conversacionais e de operadores argumentativos. Além desses, também verificamos a presença da ironia, a qual levou ao riso dos fiéis durante a pregação. Todos esses tiveram como consequência a construção de um estilo próprio, carregado de bom humor.
\end{abstract}

Palavras-Chave: Argumentação. Discurso Religioso. Pregação. Casamento.

\begin{abstract}
This article aims to identify the linguistic and discursive marks of argumentation left in the preaching "O segredo do sucesso no casamento: atentando para os detalhes". The theoretical framework is based on the concepts of Argumentative Semantics and Textual Linguistics. We carried out a bibliographical and a documentary research and then proceeded to a descriptive analysis of data. According to the findings, we highlight the intertextuality with the song "Detalhes", by Erasmo Carlos and Roberto Carlos (1971) regarding to argumentative devices, and concerning the biblical discourse, the speaker employed repetition, interrogation, conversational markers and argumentative operators. In addition, we also observed the presence of irony which made the congregation laugh during the preaching. All of these elements culminated in the construction of a unique style, full of good humor.
\end{abstract}

Keywords: Argumentation. Religious Discourse. Preaching. Marriage.

\footnotetext{
${ }^{1}$ Possui doutorado e mestrado em Estudos da Linguagem pela Universidade Estadual de Londrina (UEL) e pósdoutorado em Educação (UEPG). É professora da Universidade Estadual do Norte do Paraná (UENP) e pesquisadora do DIALE - Diálogos Linguísticos e Ensino (CNPq, UENP). E-mail: leticiajstorto@gmail.com ${ }^{2}$ Possui doutorado e mestrado em Estudos da Linguagem pela Universidade Estadual de Londrina (UEL) e pósdoutorado em Inglês: Estudos Linguísticos e Literários pela Universidade Federal de Santa Catarina (UFSC). É docente da Universidade Federal de Mato Grosso do Sul (UFMS). E-mail: vanessahburgo@hotmail.com

${ }^{3}$ Possui mestrado em Estudos da Linguagem pela Universidade Estadual de Londrina (UEL). É doutorando em Letras pela Universidade Federal de Mato Grosso do Sul (UFMS). É professor o Instituto Federal Catarinense (IFC). E-mail: eduardo.ferreira@ifc.edu.br
} 


\section{Detalhes iniciais}

“Eu sei que esses detalhes vão sumir
Na longa estrada
Do tempo que transforma todo amor
Em quase nada
Mas quase também é mais um detalhe
Um grande amor não vai morrer assim”

(Esteves; Braga, 1971)

A argumentação é parte inerente do discurso, porque o é da língua. Isso quer dizer que todo discurso, em maior ou em menor grau, é argumentativo, pois o objetivo da prática comunicativa não é apenas noticiar, mas induzir o ouvinte/ leitor a assentir o que está sendo dito a ele. Portanto, não há discurso neutro, isento de argumentatividade (KOCH, 2011).

Tomando isso em consideração, este artigo objetiva identificar os recursos linguísticodiscursivos da argumentação presentes em uma pregação religiosa midiática de cunho evangélico. Para isso, como corpus de pesquisa, selecionamos a pregação "O segredo do sucesso no casamento: atentando para os detalhes” (mais de 3.700 visualizações, publicada em 19 de jan. de 2017, duração de 47min25seg, realizada na Igreja Batista publicada no YouTube em 8 de fevereiro de 2017). A transcrição foi gerada automaticamente pela plataforma YouTube com acréscimo de alguns sinais (como reticências para marcar pausas, dois-pontos para alongamentos, interrogação para perguntas).

Metodologicamente, este trabalho classifica-se como pesquisa documental de cunho descritivo. Para sua realização, foi empregada uma pesquisa bibliográfica como auxiliar. O método de análise é o indutivo, como convém aos materiais obtidos em situações reais de interlocução (GALEMBECK, 2009). Ademais, o instrumental conceitual dos estudos linguísticos e discursivos são também metodológicos. A seguir, apresentamos brevemente algumas informações sobre igrejas evangélicas, a fim de contextualizar situação discursiva mais ampla.

\section{Breves considerações a respeito das denominações de igrejas evangélicas}

Devido às muitas denominações evangélicas existentes, foram elaboradas tipologias para classificar as Igrejas, porém essas tipologias são variadas, provisórias e insatisfatórias, além de não serem unânimes (CUNHA, 2007).

Cunha (2007) divide as comunidades evangélicas em seis grupos: Protestantismo Histórico de Migração; Protestantismo Histórico de Missão (PHM); Pentecostalismo Histórico 
(caso da Assembleia de Deus); Protestantismo de Renovação ou Protestantismo Carismático; Pentecostalismo Independente ou Neopentecostalismo (caso da Igreja Mundial do Poder de Deus e da Igreja Universal do Reino de Deus); e Pentecostalismo Independente de Renovação (caso da Igreja Internacional da Graça de Deus).

De maneira mais simples, o Instituto Brasileiro de Geografia e Estatística - IBGE (2012) dispõe as Igrejas evangélicas em dois grandes grupos: Igrejas Pentecostais e Igrejas de Missão (também conhecidas como Igrejas Tradicionais, Igrejas Reformadas e Igrejas Protestantes). Nesse grupo, figuram as Igrejas Históricas (Protestantismo Histórico de Migração, Protestantismo Histórico de Missão e Pentecostalismo Histórico), o Protestantismo de Renovação; e naquele, o Neopentecostalismo e o Pentecostalismo Independente de Renovação.

O termo “'Evangélico de Missão’ é o novo nome dado aos evangélicos tradicionais ou protestantes tradicionais pela nomenclatura utilizada pelo IBGE para o recenseamento de 2000" (JACOB et al. 2003, p.69). Segundo Cunha (2007), o protestantismo de missão originou-se na Reforma Protestante ocorrida no século XVI. Pertencem ao grupo de evangélicos de missão as seguintes Igrejas: Luterana, Presbiteriana, Metodista, Batista, Congregacional, Adventista e outras (IBGE, 2012). Essas Igrejas voltam seu trabalho para obras de missão, como o envio de missionários a grupos que se deseja converter ou de fiéis para trabalho social em comunidades carentes. Os Evangélicos de Missão organizam-se por meio de comunidades. Segundo Jacob et al. (2003, p.70), “a multiplicidade de confissões protestantes tradicionais lembra a dos Pentecostais: há uma Igreja dominante, a dos Batistas, seguida de três Igrejas de importância semelhante, os Adventistas, os Presbiterianos e os Luteranos, e, finalmente, várias outras Igrejas de menor expressão”.

De acordo com o IBGE (2012), pertencem ao grupo de evangélicos pentecostais as seguintes Igrejas: Assembleia de Deus, Congregação Cristã do Brasil, O Brasil para Cristo, Quadrangular, Universal do Reino de Deus, Casa da Bênção, Deus é Amor, Maranata, Nova Vida e outras (IBGE, 2012). Acrescentamos à lista a Igreja Mundial do Poder de Deus e a Igreja Internacional da Graça de Deus.

Pentecostal deriva de Pentecoste, que é uma festa em que se celebra o recebimento do Espírito Santo pelos cristãos; ela ocorre 52 dias após a Páscoa. Disso deriva seu nome, que, em grego, quer dizer “quinquagésimo (dia)” (KASCHEL; ZIMMER, 1999). Foi durante uma festa de Pentecoste que os fiéis, pela primeira vez, falaram em línguas estranhas (Dom de Línguas ou glossolalia). Trata-se de um “dom do Espírito Santo que permitiu a todos os apóstolos falarem em outras línguas (idiomas), sendo entendidos por pessoas de diferentes países” (KASCHEL; ZIMMER, 1999, p.130). 
As Igrejas Pentecostais recebem esse nome devido à crença nesse dom e à importância que dão ao batismo no Espírito Santo, por meio do qual recebem o Dom de Línguas. Segundo a CPAD - Casa Publicadora das Assembleias de Deus (2014, s/p), os participantes de um "reavivamento foram cheios do Espírito Santo da mesma forma que os discípulos e os seguidores de Jesus durante a Festa Judaica do Pentecostes, no início da Igreja Primitiva (Atos cap. 2). Assim, eles foram chamados de 'Pentecostais'". As Igrejas Pentecostais acreditam no relacionamento direto entre os fiéis e Deus, o que se deve à morte e ressureição de Jesus Cristo e ocorre por meio do Batismo no Espírito Santo; assim, dispensam alguns dogmas religiosos, como a confissão.

Precisamos ainda situar as igrejas evangélicas neopentecostais, grupo ao qual o discurso em tela pertence. O neopentecostalismo (ou pós-pentecostalismo) nasceu na segunda metade da década de 1970 como uma dissidência do pentecostalismo clássico - exemplo, Congregação Cristã no Brasil e Assembleia de Deus (MARIANO, 2004). “A Universal do Reino de Deus (1977, RJ), a Internacional da Graça de Deus (1980, RJ), a Comunidade Evangélica Sara Nossa Terra (1976, GO) e a Renascer em Cristo (1986, SP), fundadas por pastores brasileiros, constituem as principais igrejas neopentecostais do país” (MARIANO, 2004, p.123-124). Conceitualmente, voltam-se ao discurso da cura, enfatizam a guerra espiritual contra o diabo e seus representantes, pregam a Teologia da Prosperidade 4 , além de negar "usos e costumes de santidade pentecostais, tradicionais símbolos de conversão e pertencimento ao pentecostalismo” (MARIANO, 2004, p.124). O Neopentecostalimos apresenta um discurso menos sério e sóbrio se comparado ao discurso pentecostal clássico, do que deriva o aceite ao riso, fator argumentativo presente na pregação em análise. Trata-se do grupo evangélico com maior crescimento em número de fiéis nas últimas décadas no Brasil (IBGE, 2012). Também é responsável pelo “boom da mídia evangélica” no país entre 1989 e 1999.

Após essa contextualização, voltamo-nos ao conceito de argumentação a que nos filiamos.

\section{Os Detalhes estão na Argumentação}

\footnotetext{
${ }^{4}$ Segundo a Teologia da Prosperidade, a fidelidade a Deus e a fé nEle (simbolicamente representada pela obediência a Deus e, consequentemente, ao dízimo) “derramam” bênçãos na vida dos fiéis, ou seja, se o crente é fiel a Deus, Ele o abençoará com riquezas materiais e espirituais, como boa saúde. Trata-se também de uma teologia "difusora da crença de que o cristão deve ser próspero, saudável, feliz e vitorioso em seus empreendimentos terrenos” (MARIANO, 2004, p.124).
} 
Neste trabalho, assumimos a postura de Ducrot (1981), Anscombre e Ducrot (1980), Koch (2011) e Mosca (2004), segundo a qual a argumentação é imanente ao discurso, à língua, pertencendo-lhe, não é algo que lhe adicionamos, pois “a argumentatividade está inscrita no nível fundamental da língua” (KOCH, 2011, p.19). Para os autores, há que se ter em mente que a língua - portanto, o discurso - é essencialmente argumentativa, pois os enunciados são dotados de determinada força argumentativa, não havendo discurso sem determinado argumento subjacente. Também não há argumentos ingênuos, livres de intenção ou ideologia; portanto, não existe texto objetivo, imparcial, neutro (KOCH, 1992), em todos há, ainda que latente, certo teor argumentativo. Logo, a argumentatividade consiste em um princípio de textualidade (ANSCOMBRE; DUCROT, 1980; DUCROT, 1981; KOCH, 2011), tal qual a coerência, a coesão, a intertextualidade, podendo considerá-la como o principal deles, apresentando-se subjacente e imbrincada aos demais princípios (KOCH, 2011). Isso porque o ato de comunicação é um jogo de manipulação e o objetivo principal é fazer que o enunciatário se convença do que foi transmitido (FIORIN, 2009).

Contudo, podemos pensar em argumentação ${ }^{5}$ lato sensu e argumentação stricto sensu. Aquela considera que todo e qualquer enunciado é argumentativo, pois a vontade de interagir em si, seja por meio da fala ou da escrita, apresenta, inerentemente, um teor argumentativo, uma vez que, para nos comunicarmos com o outro, precisamos conquistar-lhe o desejo de nos ler/ouvir, de querer interagir conosco. Isso se deve ao fato de que a argumentatividade se faz presente em todo e qualquer texto/discurso "de modo mais ou menos intenso, mais ou menos explícito. Num continuum argumentativo, podem-se localizar textos dotados de maior ou menor argumentatividade, a qual, porém, não é jamais inexistente” (KOCH; FÁVERO, 1987, p.09).

Já na argumentação stricto sensu, há enunciados necessariamente argumentativos, os quais, por seu turno, formam textos pertencentes a gêneros textuais da ordem do argumentar, tais como textos publicitários em geral (propagandas), peças judiciárias (de defesa e acusação),

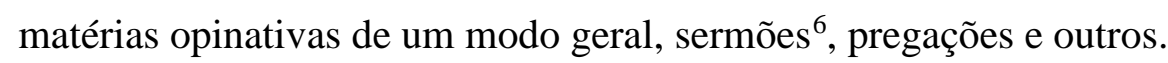

Segundo Travaglia (1991, p.58), a argumentação stricto sensu está presente em “textos em que a argumentação se apresenta de maneira explícita e atinge o seu grau máximo porque 'nele se toma posição e se propõe a debater"”. Ainda, segundo o autor, neles "se manifesta explicitamente o objetivo de convencer, persuadir, de fazer crer ou fazer fazer, pois, como se sabe, todo texto tem uma dimensão argumentativa”. Koch e Fávero (1987, p.09) afirmam que,

\footnotetext{
${ }^{5}$ Doravante, os termos argumentação e argumentatividade serão considerados como sinônimos. 6 Os últimos quatro itens foram indicados por Travaglia (1991).
} 
a argumentação stricto sensu enquadra os textos em que a argumentatividade "se apresenta de maneira mais explícita e atinge o seu grau máximo”. Por isso, propõe-se o seguinte quadro:

\section{TEXTOS/ DISCURSOS}

\begin{tabular}{|c|c|c|}
\hline $\begin{array}{c}\text { ARGUMENTATIVOS } \\
\text { STRICTO SENSU }\end{array}$ & $\&$ & ARGUMENTATIVOS \\
LATO SENSU \\
(ou NÃO STRICTO SENSU)
\end{tabular}

Quadro 1: Textos/ Discursos Argumentativos Stricto e Lato Sensu

Fonte: Os autores.

Isso porque a argumentação realiza-se de diversas maneiras nos textos e nos discursos (TRAVAGLIA, 1991). A argumentação é entendida como a “ação pela linguagem por meio da qual se tenta levar o(s) interlocutor(es) a determinados tipos de conclusão ou de comportamento” (KOCH, 1985, p.173). Nesse sentido, ela é assumida como um meio para dirigir os interlocutores, uma ação por meio da qual visamos à concordância dos espíritos, à adesão (PERELMAN; OLBRECHTS-TYTECA, 2005).

A argumentação "é o estudo das técnicas discursivas que permitem provocar ou aumentar a adesão dos espíritos às teses que se lhes apresentam ao assentimento" (PERELMAN; OLBRECHTS-TYTECA, 2005, p.04 - grifos dos autores); logo, devemos considerar a adesão dos espíritos o principal objetivo da argumentação. Assim, este trabalho tem como objetivo analisar as marcas linguístico-discursivas do discurso religioso midiático que buscam ampliar a adesão do auditório. Segundo Ducrot (1981, p. 178),

O valor argumentativo de uma frase não é somente uma consequência das informações por ela trazidas, mas a frase pode comportar diversos morfemas, expressões ou termos que, além de seu conteúdo informativo, servem para dar uma orientação argumentativa ao enunciado, a conduzir o destinatário em tal ou qual direção.

Dentre as marcas linguístico-discursivas argumentativas deixadas no discurso, podemos citar: os intertextos, as pressuposições, as modalizações, os operadores argumentativos, os marcadores discursivos, as imagens e máscaras apresentadas/mostradas pelos falantes, os dêiticos, os adjetivos, os argumentos de autoridade etc. No discurso, esses elementos coadunam-se e misturam-se na e para a construção de sentidos, muito embora em algumas situações possamos valorizar mais um elemento do que outro com vistas a atingirmos os nossos objetivos interacionais. Na seção seguinte, analisamos os detalhes da argumentação em um texto oral pertencente ao gênero pregação de um pastor bastante conhecido por suas pregações bem-humoradas. 


\section{Casamento em detalhes: análise do corpus}

Antes de iniciarmos a análise, cumpre apresentar o sujeito produtor desse discurso. $\mathrm{O}$ Pr. Cláudio Duarte nasceu em 9 de maio de 1951, é casado, pai de dois filhos e avô. "Converteuse na Igreja Batista Brasileira em 1992, onde trabalha até hoje” (DUARTE, 2020, s/p). Segundo ele, sua conversão se deu em um momento de dificuldades pessoais que o levaram a um encontro com Deus. Como afirmado na página eletrônica do pastor, ele se tornou uma figura pública e ganhou destaque ao ter suas pregações divulgadas na internet (DUARTE, 2020). Pode-se dizer que uma marca forte do discurso desse religioso é o humor, o que tem atraído não somente o público evangélico, mas também católico e não religioso (DUARTE, 2020). Esses motivos (popularidade, aceitação etc.) justificam a escolha de uma pregação do pastor como objeto de estudo.

O primeiro recurso argumentativo apresentado no texto em análise está no título (“O segredo do sucesso no casamento: atentando para os detalhes”) e se classifica como sendo um recurso de intertextualidade. A intertextualidade é o diálogo entre textos. Esse fator de textualidade integra as variadas maneiras pelas quais a produção/ recepção de um determinado texto advém do conhecimento de outros textos (KOCH, 2009). Já no título da pregação há presença desse diálogo entre textos. Nele, há o termo “detalhes”, trata-se de uma intertextualidade implícita com o título de uma canção brasileira muito conhecida, qual seja: “Detalhes”, composição de Erasmo Esteves (nome artístico: Erasmo Carlos) e Roberto Carlos Braga (nome artístico: Roberto Carlos). Para perceber esse diálogo, o interlocutor - no caso, os fiéis que estão na igreja durante a pregação e, depois, quem assiste ao vídeo disponível no YouTube - precisa ter o conhecimento prévio da música para estabelecer a relação entre os dois textos (o título da pregação e o título da canção). No título, essa intertextualidade aparece implicitamente, o ouvinte precisa recorrer à sua memória discursiva para se lembrar do textofonte (ou intertexto) e estabelecer os objetivos para o diálogo textual (KOCH, 2009).

Quando o pastor traz essa informação no texto, transforma sua intertextualidade em explícita: “01:21 esse porque as coisas são decididas nos// 01:24 detalhes// 01:25 como diria

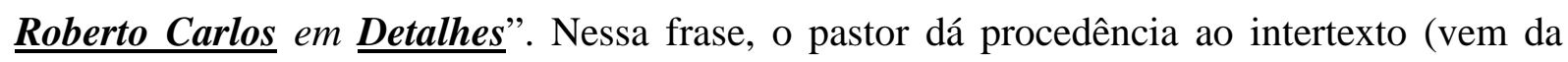
canção "Detalhes", interpretada por Roberto Carlos), levando o auditório ao riso, provavelmente porque ainda não havia percebido a relação entre os textos, também porque, em um contexto religioso (mais conservador), é trazido o discurso da cultura, da música popular brasileira (menos conversador). 


\section{Excerto 1}

01:21 porque as coisas são decididas nos

$01: 24$ detalhes

01:25 como diria Roberto Carlos... Detalhes

Pregação "O segredo do sucesso no casamento: atentando para os detalhes” (Pr. Cláudio Duarte)

A relação com a música detalhes permeia toda a pregação do pastor, de modo a essa expressão ser reiterada no texto (15 ocorrências). O termo “detalhes” remete o ouvinte às minúcias de algo, às “coisas pequenas...”, como disse o pastor. Contextualizando ao tema da pregação, desvela-se que, a fim de se manter uma união/ um casamento, é preciso estar atento a todas as particularidades, as pequenas “coisas” de rotina de um casal, ou seja, aos detalhes, como "O ronco barulhento do seu carro// A velha calça desbotada ou coisa assim” (ESTEVES; BRAGA, 1971). No próximo excerto, há um trecho da pregação em que o pastor recorre a outro texto (a um provérbio) como recurso argumentativo: 


\section{Excerto 2:}

00:18 isso espera quem espera sempre alcança

00:20 amém?

O provérbio “quem espera sempre alcança” integra a memória coletiva (social) da comunidade. Por meio de seu emprego na pregação, o pastor recorre ao conhecimento de mundo do auditório, a fim de relacionar o tópico da pregação (casamento) ao dito popular, enfatizando que a espera é gratificada, ou seja, quem esperar em Deus conseguirá um (bom) casamento. Ao terminar a unidade discursiva com o “amém”, marcador conversacional típico do discurso religioso, o pastor busca a concordância do auditório com seu discurso, a adesão àquilo que ele diz, ou seja, “quem espera um casamento em Deus será recompensado”. Ao responder com o uso do mesmo marcador conversacional, o auditório manifesta verbalmente o aceite da mensagem e a sua concordância com o discurso do pastor (Excerto 2).

Nesse trecho da pregação, além do emprego de um marcador conversacional como recurso argumentativo, o “amém”, há também a repetição como marca linguístico-discursiva de argumentação, recurso muito presente em toda a pregação e que funciona em geral como um intensificador discursivo. Há vários momentos de repetições na pregação em análise (como se vê no Excerto 3 e no 4), o que é comentado pelo próprio pastor: “01:04 eu vou ser repetitivo// 01:05 em algumas coisas... mas nunca é demais// 01:08 você ouvir... ouça... Deus gosta de repetir// 01:13 os Evangelhos repetem” (Pr. Cláudio Duarte).

\section{Excerto 3}

00:18 isso espera quem espera sempre alcança

00:20 amém?

00:23 case-se case-se case-se

00:25 casar é bom

00:28 só que tem que casar com a pessoa certa

00:31 melhor do que ser solteiro pior do que

00:34 ser solteiro é ser mal casado

00:37 então espere espere espere e Deus vai

00:39 enviar fica com pressa não meu filho não

00:43 se não você casa com a pessoa errada aí já era

\section{Excerto 4}

35:38 a mulher brasileira também cria filho pra casar com ela... sabe...

35:45 tem um ciúme do filhinho... o irmão falou muito

35:48 sabiamente... nós criamos filhos para viver

35:51 a vida deles...

35:56 é assim que funciona... sabe...você sabia que que o ser

36:02 humano é único animal na face da Terra

36:03 que tem neto... nenhum outro animal tem neto 
No contexto citado, a repetição tem três objetivos: esclarecer/ corrigir algo (“00:31 melhor do que ser solteiro pior do que// 00:34 ser solteiro é ser mal casado") e ressaltar o que é dito (“00:37 então espere espere espere e Deus vai”) e buscar a adesão do auditório, que se confirma pelo retorno dado por risos, gestos e palmas (objetivo que abraça os dois anteriores). A repetição tem papel argumentativo porque atua como reforço da argumentação.

Em "00:23 case-se case-se case-se” e "00:37 então espere espere espere e Deus vai”, há repetição lexical. Enquanto figura de linguagem, essas repetições classificam-se como uma anáfora, a qual se caracteriza pela repetição de uma ou mais palavras no início de unidades discursivas, versos, orações ou períodos. Com essas repetições, o pastor intensifica aquilo que é dito, marcando na mente do interlocutor a ideia de que casar é algo positivo, tão positivo que é algo por que vale a pena esperar (ainda que a espera demore, sentido emanado da repetição do verbo esperar em “espere espere espere”).

No Excerto 3, a repetição é adjacente, ou seja, as palavras repetidas estão seguidas, muito próximas (“espere espere espere”). Já no Excerto 4, isso nem sempre ocorre: algumas repetições estão distantes entre si. Exemplo disso é o "saber" (conjugado) que, nesse trecho da pregação, aparece três vezes em momentos não adjacentes (17 repetições em toda a pregação). Esse tipo de repetição se mostrou mais constante na pregação do pastor. Outro modo de repetição comum nos textos analisados é a retomada da raiz do vocábulo: no excerto, há repetição em palavras de classe gramatical distinta: “śabe” e "sabia” (verbo “saber” conjugado) e "sabiamente” (advérbio). A repetição, como se mostrou nesses trechos, é um recurso textual muito utilizado em textos orais, caso de pregações religiosas, o que vai ao encontro do que os teóricos da fata têm afirmado: a repetição é uma das principais estratégias de reformulação textual dos textos, especialmente os falados, e assume um variado conjunto de funções (MARCUSCHI, 2002). Em relação à argumentatividade, as repetições, principalmente as oracionais, têm papel primordial na construção da argumentação, servem como estratégias para reafirmar, contrastar ou contestar argumentos (MARCUSCHI, 2002).

Em alguns momentos no texto, a esse recurso (repetição) é dada uma voz de autoridade (a maior delas no discurso religioso), a voz de Deus: "01:08 você ouvir... ouça ... Deus gosta de repetir// 01:13 os Evangelhos repetem” (Pr. Cláudio Duarte). Ao atrair a voz de autoridade (outro recurso argumentativo), aquilo que é dito pelo pastor ganha força ilocutória e perde poder de contestação, afinal Deus, no discurso religioso, é incontestável, soberano.

Essa voz de autoridade também é retomada nas citações bíblicas (excertos que seguem) e na referência ao texto bíblico, as quais também se caracterizam como intertextos. Logo, ao 
citar o texto bíblico, o pastor recorre a dois recursos argumentativos: voz de autoridade e intertextualidade. Juntos essas estratégias colaboram para a adesão do auditório ao discurso.

\title{
Excerto 5
}

08:28 então eu quero que você abra sua bíblia

08:32 vamos onde tudo começou na raiz do problema

08:36 Gênesis 2 verso 18

\author{
Excerto 6 \\ 08:48 pois foi o que Deus colocou no \\ 08:54 meu coração \\ 08:55 Gênesis 2:18 amém
}

Além desses recursos, no texto em tela, nota-se a presença de pronomes, advérbios e conjunções, os quais funcionam no texto como operadores argumentativos. No texto em análise, o advérbio de lugar "aqui” e o de tempo "hoje” apresentam-se como dêiticos, aquele espacial e esse temporal, marcando, assim, a posição do referente no tempo e no espaço: "10:28 falei isso aqui hoje eu quero repetir”, “00:00 quem aqui é casado levante a mão glória// [...] 00:12 tenha misericórdia de quem aqui ainda”, "00:49 então hoje eu quero trabalhar com vocês// [...] 01:00 hoje eu quero trabalhar essa dinâmica”. Os advérbios ou locuções adverbiais indicam a dêixis discursiva, que pode ser temporal (ontem, hoje, amanhã), espacial (aqui, ali, acolá) ou pessoal (eu, você/ tu, ele). Para Fiorin (2009, p.62), os advérbios de tempo são enunciativos, eles apontam "o dia anterior ao dia em que se fala, o dia em que se faz a enunciação e o dia posterior ao dia da produção do discurso”. Os advérbios de espaço mostram se o lugar é perto do falante, do ouvinte ou do referente (de que se fala, da $3^{\mathrm{a}}$ pessoa).

Já o pronome pessoal de primeira pessoa “eu” e possessivo de primeira pessoa "meu” sinalizam a pessoa do pastor no discurso: "08:28 então eu quero que você abra sua bíblia"; “08:54 $\underline{\text { meu }}$ coração”. Esses operadores colaboram com a condução do discurso, seu direcionamento. Ao se colocar no texto, o falante busca impõe a sua autoridade; ao trazer o discurso para a primeira pessoa, ele busca trazer "personalidade”, comprometendo-se com aquilo que diz, de modo a aumentar a força ilocutória do seu discurso, contribuindo para a adesão do auditório à ideia apresentada. Com isso, o pregador ocupa o lugar de articulador entre os fiéis e Deus. Além de se colocar no discurso, o pastor também insere nele o seu auditório. Para isso, recorre a algumas estratégias: a) pronomes de segunda pessoa (você, tu); b) verbos direcionados à segunda pessoa do discurso; c) perguntas.

Na pregação em tela, a interrogação também é muito utilizada como recurso argumentativo e interacional, pois exige uma resposta do interlocutor, o qual colabora 
ativamente, como se vê no próximo excerto. Nesse mesmo trecho, há ocorrência do pronome de segunda pessoa “tu” e de verbos direcionados à segunda pessoa (“pode”, “morra”). Além da segunda pessoa, a primeira pessoa do plural (nós) também chama o auditório para o discurso, mas sem marcar a distinção “eu” versus “tu”. Com o nós - seja na forma de pronome, seja na desinência verbal (“podemos”) -, o pastor coloca-se no mesmo patamar que seus fiéis, agora eles são um só grupo. Isso colabora (e muito) para a adesão do auditório ao discurso que é dito.

\section{Excerto 7}

01:35 se tu não pode, morra

01:42 e nós podemos melhorar ou não

Além desses recursos, a ironia se faz presente na pregação, contribuindo com a construção de um ambiente de bom-humor, como se vê no Excerto 7, no qual o pastor utiliza o verbo “morrer” (“morra”) no imperativo de modo irônico e exagerado/ hiperbólico. A ironia pode ser definida como "a uma espécie de antífrase cujo sentido é captado por meio da polifonia [várias vozes] nela presente” (OLIVEIRA; MACHADO, 2013, p.13), isto é, presença de muitas/diferentes (“poli”) vozes (“fonia”), as quais colaboram para a construção de sentidos diversos e até contraditórios, já que a ironia é também a apresentação de uma não verdade (MACHADO, 2014). Isso porque "um enunciado irônico tem o objetivo de dizer algo diferente do que foi dito e está sempre relacionado ao campo do humor, seja para dizer de forma depreciativa, polêmica ou mesmo séria” (OLIVEIRA; MACHADO, 2013, p.13). Apesar de o humor ser bem-visto, a ironia nem sempre é bem recebida, porque pode apresentar tom de grosseria e até crueldade (MACHADO, 2014). Seu emprego pode visar a proteger o falante de sanções que enunciados mais diretos receberiam (MACHADO, 2014).

Certamente, nesse excerto, o falante não desejava que seus ouvintes morressem por não poderem melhorar. Além disso, assim como expõe Machado (2014), a ironia pode surgir sem ser esperada pelos interlocutores. Provavelmente, os fiéis não esperavam esse comentário do pastor. A surpresa levou os fiéis ao riso (audível no vídeo), elemento que também pode ser entendido como um recurso argumentativo para o envolvimento do auditório, já que colabora para sua persuasão. Além disso, “o riso é o efeito do cômico e ambos estão situados no campo do humor, por isso, só é possível entender o riso em seu ambiente natural, que é a sociedade” (OLIVEIRA; MACHADO, 2013, p.12). Durante a pregação do pastor, há vários momentos que levam ao riso dos fiéis, o que pode ser percebido ao se ouvir o áudio da gravação. O riso funciona como uma figura de comunhão, ou seja, ele busca aproximar o auditório do locutor (MARIANO, 2005). Esse recurso tem ainda o papel de contribuir para diminuir a tensão de um discurso sério, como o religioso, que apresenta caráter moralizante e moralizador de forma 
intrínseca. "Nas situações discursivas mais formais pode-se buscar a adesão do auditório por meio do riso ou da graça, alguns dos efeitos possíveis do inesperado” (MARIANO, 2005, p.1242).

O aspecto feliz representado pelo riso funciona como estratégia argumentativa em interações faladas face a face ou virtuais. Isso porque as pessoas desejam criar vínculos com os outros e o sorriso significa abertura à relação social, a ausência de medo ou de raiva. O sorriso transmite uma sensação agradável, de prazer; com o sorriso, os locutores se mostram favoráveis ao outro, a se aproximar dele. Para Souza (2012, p.2654), “a graça na 'espetacularização religiosa', proposta pela televisão, transforma sentidos normalizados sobre o comportamento litúrgico no espaço sagrado, pois ressignifica uma manifestação que historicamente é reconhecida como marca inerente do humano, portanto do mundano, do profano - o riso”.

Com isso, o riso aproxima o que divino do que é humano, tornando o discurso religioso mais próximo daquele que ele precisa atingir. Assim, com o riso, o discurso religioso se atualiza, de modo a se refazer "no imaginário social a imagem do crente enquanto sisudo ou infeliz historicamente postulada” (SOUZA, 2012, p.2653). Para a autora, as imagens de riso em pregações seriam uma "prova visível de uma igreja alegre, satisfeita. Mostrar as imagens significa autenticar, fazer crer que é possível ser crente e não ser infeliz, não ser oprimido” (SOUZA, 2012, p.2650).

A ironia e o paradoxo (figura de linguagem que "funde" elementos/ discursos contraditórios, opostos) se fazem presentes também no enlaçamento e no imbricamento entre discursos inconciliáveis: discurso sacro (pregação religiosa) e discurso profano (música popular brasileira). Ao trazer a música para seu texto, o pastor concatena dois universos que, a priori, estariam distantes e seriam opostos. Tais contrastes também servem como recursos argumentativos, na medida em que recriam no interlocutor o próprio paradoxo da existência humana e dos discursos que têm circulado há anos na sociedade, os quais buscam entender essa importante relação que há entre Deus (ou os deuses) e os Homens.

Assim, o afastamento do homem das coisas mundanas é considerado um processo de sacralização, em que o que é mundano (do mundo) e, por conseguinte, profano (não sagrado, não pertencente à religião) deve ser distanciado do que é divino (de Deus), ambos os universos (mundano/profano e divino) não se misturam. Contudo, esse afastamento tem sido relativizado, atualizado (VITAL; LOPES, 2013). “Ou seja, a globalização (e o processo de subjetivação/individualização nela forjado) e o crescimento da presença evangélica na mídia televisiva contribuíram para o surgimento de novas formas de "ser evangélico" (VITAL; LOPES, 2013, p.37). Porém, isso não quer dizer que o discurso de afastamento esteja anulado, 
mas que o novo (afastamento modernizado/atualizado) e o antigo (afastamento) não se excluem, eles “se somam, convivem com os 'antigos' modos de se 'viver a fé' cristã (seja entre os evangélicos, seja entre os católicos)”. Trata-se de um modo que os religiosos encontraram para sacralizar o que era mundano e, portanto, profano aos seus olhos, de modo que se mantivessem “o máximo de tempo possível num universo sagrado” (ELIADE, 1992, p.14).

Enfim, no texto em análise, o falante, no caso um pastor evangélico, emprega variados recursos argumentativos, construindo um estilo próprio e engraçado de pregar, o que tem colaborado para a sua visibilidade em contexto nacional.

\section{Últimos detalhes...}

O discurso religioso midiático é bastante significativo e está muito presente na sociedade contemporânea, na qual interfere em questões variadas, colabora para a construção de sentidos, a organização das comunidades, a produção de saberes, entre outros. Nesse contexto, o discurso evangélico tem se sobressaído, de forma que o Brasil pode ser compreendido como um país de evangélicos.

Em vista disso, investigamos algumas marcas da argumentação presentes em uma pregação a respeito de casamento. Observamos também que o emprego de recursos distintos (como intertextualidade, marcadores conversacionais, repetições, operadores argumentativos etc.) colabora para a construção de um contexto argumentativo. Para falar de casamento, o pastor também recorre à ironia e ao bom humor, levando seus fiéis ao riso. Todos esses detalhes em coerência contribuem para o processo de persuasão dos interlocutores.

\section{REFERÊNCIAS}

ANSCOMBRE, Jean-Claude; DUCROT, Oswald. L'argumentation dans la langue. Langages, 42, Paris, 1980 [1976]. p.5-27.

CUNHA, Magali do Nascimento. A explosão gospel: um olhar das ciências humanas sobre o cenário evangélico no Brasil. Rio de Janeiro: Mauad X/Instituto Mysterium, 2007.

DUARTE, Cláudio, Pr. A pessoa Cláudio Duarte. Disponível em: http://www.claudioduarte.com.br/o-bom-humor-na-missao-evangelizadora-do-pastor/. Acesso em: maio 2021.

DUARTE, Cláudio, Pr. (2017). O segredo do sucesso no casamento: atentando para os detalhes. Série Mensagem Diante do Trono. Disponível em: https://www.youtube.com/watch?v=waV6tSWrPwA. Acesso em: maio 2021.

DUCROT, Oswald. Provar e dizer: linguagem e lógica. Tradução de Tradução de Maria Aparecida Barbosa, Maria de Fátima G. Moreira e Cidmar Teodoro País. São Paulo: Global Universitária, 1981. 
ELIADE, Mircea. O sagrado e o profano. Tradução de Rogério Fernandes. São Paulo: Martins Fontes, 1992.

ESTEVES, Erasmo; Braga, Roberto Carlos. (1971). Detalhes. Disponível em: https://www.vagalume.com.br/roberto-carlos/detalhes.html. Acesso em: maio 2021.

FIORIN, José Luiz. Elementos de Análise do Discurso. 14.ed. 2.reimp. São Paulo: Contexto, 2009.

GALEMBECK, Paulo de Tarso. Metodologia de pesquisa em português falado. In: Rodrigues, Ângela Cecília de Souza et al (Orgs.). I Seminário de Filologia e Língua Portuguesa. (p.109119). São Paulo: Humanitas/ FFLCH/ USP, 1999.

IBGE - Instituto Brasileiro de Geografia e Estatística. Censo 2010: número de católicos cai e aumenta o de evangélicos, espíritas e sem religião. (2012). Disponível em: http://censo2010.ibge.gov.br/noticias-censo?busca=1\&id=3\&idnoticia=2170\&view=noticia .

Acesso em: maio 2021.

JACOB, Cesar Romero et al. Atlas da filiação religiosa e indicadores sociais no Brasil. Rio de Janeiro: Loyola, 2003.

KASCHEL, Werner; ZIMMER, Rudi. Dicionário da bíblia de Almeida. 2.ed. Barueri, SP: Sociedade Bíblica do Brasil, 1999.

KOCH, Ingedore Grunfeld Villaça. Argumentação e linguagem. 13. ed. São Paulo: Cortez, 2011.

KOCH, Ingedore Grunfeld Villaça. Introdução à linguística textual: trajetória e grandes temas. 2.ed. São Paulo: Martins Fontes, 2009.

KOCH, Ingedore Grunfeld Villaça. A inter-ação pela linguagem. São Paulo: Contexto, 1992.

KOCH, Ingedore Grunfeld Villaça. Situacionalidade e argumentatividade. In: SEMINÁRIO DO GEL, 11, São José do Rio Preto, SP. Anais... São José do Rio Preto, SP, GEL, 1985, p.168170.

KOCH, Ingedore Grunfeld Villaça; FÁVERO, Leonor Lopes. Contribuição a uma tipologia textual. Letras, Uberlândia, n. 3, v. 1, p.03-10, 1987.

MACHADO, Ida Lucia. A ironia como estratégia comunicativa e argumentativa. Bakhtiniana, São Paulo, n. 9 (1), p.108-128, jan./jul., 2014.

MARCUSCHI, Luiz Antônio. A repetição na língua falada como estratégia de formulação textual. In: $\mathrm{KOCH}$, Ingedore G. Villaça (Org.). Gramática do português falado: desenvolvimentos. (p.95-140). 2. ed. rev. Campinas: Ed. da UNICAMP; São Paulo: FAPESP, 2002.

MARIANO, Márcia Regina Curado Pereira. Retórica e humor: o riso como estratégia argumentativa. In: SEMINÁRIO DO GEL, 34, São Paulo. Anais... São Paulo: GEL, 2005, p. 1242-1247.

MARIANO, Ricardo. Expansão pentecostal no Brasil: o caso da Igreja Universal. Estudos Avançados. São Paulo, v.18, n.52, p.121-138, dez. 2004. 
MOSCA, Lineide do Lago Salvador. Velhas e novas retóricas: convergências e desdobramentos. In: Mosca, Lineide do Lago Salvador (Org.). Retóricas de ontem e de hoje. 3.ed. São Paulo: Humanitas, 2004, p.17-54.

OLIVEIRA, Esther Gomes de; MACHADO, Rosemeri Passos Baltazar. O ethos em (cena): a força argumentativa do humor. Verbum: Cadernos de Pós-Graduação, Campinas, n. 3, p. 424, 2013.

PERELMAN, Chaim; OLBRECHTS-TYTECA, Lucie. Tratado da argumentação: a nova retórica. Tradução de Maria Ermantina de Almeida Prado Galvão. 2.ed. São Paulo: Martins Fontes, 2005.

SOUZA, Catiane Rocha Passos de. Religião midiatizada: uma análise discursiva do "riso". In: CONGRESSO NACIONAL DE LINGUÍSTICA E FILOLOGIA - CNLF, 16, Rio de Janeiro. Anais... Rio de Janeiro: CiFEFiL, 2012, p. 2646- 2656.

TRAVAGLIA, Luiz Carlos. Um estudo textual-discursivo do verbo no português do Brasil. (Tese de Doutorado). Universidade Estadual de Campinas, Campinas, 1991.

VITAL, Christina; LOPES, Paulo Victor Leite. Religião e política: uma análise da atuação de parlamentares evangélicos sobre direitos das mulheres e de LGBTs no Brasil. Rio de Janeiro: Fundação Heinrich Böll \& Instituto de estudos da Religião (ISER), 2013. 